\title{
El laberinto de la participación juvenil: estrategias de implicación ciudadana en la juventud ${ }^{1}$.
}

\author{
FRANCISCO JOSÉ FRANCÉS GARCÍA. \\ INSTITUTO UNIVERSITARIO DE DESARROLLO SOCIAL Y PAZ. \\ UNIVERSIDAD DE ALICANTE.
}

\begin{abstract}
Resumen
El estudio de la participación juvenil supone un reto investigador, por cuanto las prácticas colectivas de los jóvenes se contextualizan en el marco de la participación ciudadana adulta, pero presentando elementos y potencialidades propias del a condición juvenil. El artículo pretende asumir el vínculo entre reproducción del orden social y producción de nuevos órdenes en las prácticas sociales de los jóvenes, para cuestionar los enfoques teóricos que plantean una desafección pública de la juventud contemporánea. Para ello se exponen las limitaciones y disfuncionalidades del modelo participativo actual y se proponen elementos que configurarían las condiciones neecsarias para la implicación ciudadana de los jóvenes, a través del avance en tres dimensiones básicas de los procesos participativos innovadores: inclusividad, intensidad e influencia
\end{abstract}

Palabras clave: Juventud, participación ciudadana, democracia, aproximación participativa, implicación ciudadana.

\begin{abstract}
The study of youth participation is a challenge, because the collective practices of young people are contextualized within the framework of adult citizen participation, but submitting own elements and potentials of youth condition. This article attempts to assume the link between reproduction of social order and production of new orders in the social practices of youth, questioning theoretical approaches that pose a public disaffection of contemporary youth. So we will expose the limitations and dysfunctions of the current participatory model and propose elements that shape the necessary conditions for citizen involvement of young people, using three basic dimensions of participatory processes: inclusiveness, intensity and influence.
\end{abstract}

Keywords: Youth, civic participation, democracy, participatory approach, citizen involvement.

\footnotetext{
${ }^{1}$ Este artículo parte de las conclusiones de los seminarios realizados dentro de la Acción Complementaria "Las Fuentes de Identidad en el Siglo XXI", con ref. SEJ2007-29536-E, financiada por el Ministerio de Educación y Ciencia.
} 


\section{Introducción}

Enfrentarse a un fenómeno como es el estudio de la juventud supone acercarse a un actor social cuyos límites están muy claros en el imaginario colectivo, pero en la realidad se muestran difusos, difíciles de encerrar y operativizar. A pesar de que la dimensión edad es quizás la que más aproximación ofrece, la palabra "juventud" no deja de ser básicamente una construcción social que trasciende en mucho el mero hecho biológico.

Los ritos de transición entre la infancia y la juventud, y entre ésta y la edad adulta han ido cediendo lugar a una multiplicidad de situaciones que caracterizan el ser joven: ¿en qué momento el "niño" pasa a ser "joven"? ¿y cuándo asumimos que un "joven" es ya un "adulto"?. La condición juvenil ha sido objeto de una apropiación cultural por parte de nuestra sociedad, que le ha ido dotando de una serie de connotaciones simbólicas dejando de ser específicas de la edad: uno puede "sentirse joven", tener un "look joven", ser "joven de espíritu"... La juventud posee un significado compartido pero presenta múltiples significantes que hacen referencia a esta etiqueta de lo abstracto.

Como vemos, parece por lo tanto poco apropiado utilizar como referente la dimensión cultural para definir qué es la juventud. Podríamos utilizar entonces otro de los criterios habituales, el de la determinación de la situación socioeconómica de los sujetos para intentar acotar la idea de joven. De acuerdo con este planteamiento una persona realiza la transición entre juventud y edad adulta cuando posee autonomía económica y social, creando un entorno vital independiente de la familia de origen. Pero la realidad nos invalida gran parte de esta proposición. El eje cronológico tradicional que presupone una evolución entroncada por la educación, el trabajo, el establecimiento de una pareja estable y el matrimonio es una guía que ha dejado de ser válida para describir la trayectoria de muchos jóvenes, asentándose en la actualidad un modelo de prolongación de la estancia en el hogar paterno, dificultad para hallar un hueco estable en el mercado laboral, situaciones de convivencia diversas, etc.

En cualquier caso contemplamos un contingente que, bajo la perspectiva de intentar imbricar en todo momento el hecho social y biológico del colectivo, y tomando como objeto de estudio el campo de la participación juvenil, es protagonista en gran medida de lo que se ha dado en llamar la nueva condición juvenil. Y esta condición juvenil refleja una serie de paradojas que nos pueden ayudar a comprender el paradigma de complejidad al que nos enfrentamos.

A la vez que un proceso de transición a la edad adulta, parece claro que la juventud es sentida por sus protagonistas como una etapa vital, vivencial : la juventud es al mismo tiempo estadio y estado. Estadio en tanto que el mundo adulto enmarca al joven en una serie de espacios institucionalizados (familia, instituto, trabajo) a través de los cuales el joven se va convirtiendo progresivamente en adulto. El proceso de inserción del joven en su realidad inmediata necesita de un gran esfuerzo de adaptación a la diversidad de contextos en los que se debe manejar, debiendo compartir relaciones afectivas, de intercambio material, de definición de estatus, etc. Cualquier aspecto de la vida del joven al que nos acerquemos estará definido por esta multiplicidad de facetas. 
Pero cualquier sujeto vivencia con gran intensidad esta etapa juvenil. Es consciente de que asiste a una socialización productiva presidida por el "deber ser", aunque a través de su experiencia engarza estas metas deseables socialmente que permiten la reproducción social con grandes dosis de des-producción de este orden, ligadas generalmente al mundo afectivo y de relaciones sociales del joven, que en muchas parcelas se construye y se desarrolla al margen de los adultos. Este "descontrol controlado" permite al joven compartir las esferas del deber y del placer, administrando espacios y tiempos.

Así el joven de la sociedad actual se haya ante una trayectoria hacia la vida adulta en la que debe ir descubriendo los caminos, caminos que no están marcados ya que los patrones tradicionales han dejado de ser válidos, construyendo una condición juvenil distinta a la definida durante las décadas anteriores. Esta incertidumbre con frecuencia genera perplejidad en el mundo adulto, porque las explicaciones tradicionales ya no sirven para comprender muchas pautas de comportamientos, sobre todo aquellos que generan peligrosidad social o riesgo de desviación en la socialización deseable.

Por eso es de especial interés como investigadores tener acceso a los modos en que los individuos (como actores individuales o grupales relacionados con el mundo juvenil) se ven a sí mismos, a sus interlocutores, representantes, a las instituciones implicadas y al mundo que les rodea. En otras palabras, cuál es la definición social de la situación en todo aquello que tiene que ver con el joven y cómo se construye socialmente esa realidad, especialmente en el marco de sus redes de relaciones grupales.

Y la participación social o ciudadana es sin duda una de las dimensiones a través de las cuales los jóvenes construyen su universo de relaciones grupales y definen imaginarios de la realidad social. Dentro de esta perspectiva trataré de contemplar a los jóvenes como agentes sociales con entidad propia, como miembros de grupos formales o informales y como actores individuales, que desarrollan en diverso grado estrategias, modos, alternativas implicaciones en los canales participativos en sentido amplio, de acuerdo con unas expectativas grupales o sociales, con unas experiencias pasadas y con una actitud ante otros actores sociales que, por su participación o no participación, construyen esa definición de la situación a la que pretendemos acercarnos.

La reacción de distintos jóvenes ante la imagen juvenil socialmente construida por los adultos es un indicador fundamental del lugar del joven en las sociedades de países desarrollados. En este contexto, se hace imprescindible conocer de primera mano las diferentes perspectivas, los distintos paraqués y finalidades de los actores con el fin de poder identificar con claridad el estado de la cuestión: cuáles son los posicionamientos, los bloqueos, las inercias, las problemáticas y las expectativas de los distintos actores, qué elementos los caracterizan y cómo se afrontan los procesos participativos juveniles, dónde se encuentran los nudos o puntos de conflicto y dónde las potenciales alianzas o conjuntos de acción que se pueden constituir como motor de la participación juvenil.

El propósito no es otro que tratar de reducir progresivamente los desajustes entre los objetivos planteados por los intentos parciales o sectoriales de ofrecer "políticas" (servicios, más propiamente) a los jóvenes en diversas materias y las demandas (generalmente heterogéneas y difícilmente identificables) de la población juvenil en su relación con las instituciones, entendidas éstas en un sentido amplio. 
Las políticas de juventud son -valga la redundancia- una materia muy joven, débil, sujeta generalmente a cierta provisionalidad, limitada, pero al mismo tiempo y como consecuencia se abren en torno a ellas grandes posibilidades y alternativas para las cuales es posible sentar bases progresivamente, con aportaciones realmente participativas. Así mismo, la sociología de la juventud se enfrenta en estos momentos a nuevos retos ante una población juvenil caracterizada por una creciente complejidad y heterogeneidad que requiere de nueva producción teórica alimentada por la práctica.

\section{Algunos cambios a tener en cuenta en los procesos de participación juvenil.}

El primer problema al que nos enfrentamos cuando nos acercamos a la idea de lo que entendemos por participación social es precisamente su conceptualización. El término "participación" es uno de los conceptos más utilizados no solo en investigación social, sino en el marco de las políticas sociales y en el de las democracias representativas en general; pero este mismo uso y abuso que se hace del término es precisamente lo que dificulta su definición. A pesar de que parece que existe un consenso postmoderno en torno a su deseabilidad, ésta se aborda desde una enorme diversidad de enfoques e ideologías (desde el neoliberalismo hasta las perspectivas comunitaristas), otorgando un carácter polisémico al hecho participativo. De esta forma bajo el uso de un mismo significante descansan lógicas y contenidos muy diversos, cuando no enfrentados.

Si descendemos al nivel semántico de los conceptos, podemos entender enseguida que "participar" es tomar parte en algo, pero en la tradición democrática española y en la legislación que dispone, el ciudadano toma parte en la mayoría de las ocasiones por invitación, y casi siempre sin capacidad de decisión, lo que cuando menos contribuye a cuestionar la legitimidad y efectividad de estos órganos o espacios de participación. La representación de la "voluntad general" descansa en manos de las autoridades, que son las que gestionan los recursos, quedando las organizaciones ciudadanas como meros consultores que normalmente solo pueden influir en la gestión pública "por irrupción" en un momento determinado, utilizando otros cauces no previstos por la administración (campañas, manifestaciones, movimientos ciudadanos, etc.)

La complejidad de las reflexiones en torno al concepto de participación ciudadana se agrava aún más debido a la terminología al uso en este campo, cuando para referirnos a los actores utilizamos conceptos neutros y generalistas (ciudadano, administración, juventud para el caso que nos ocupa, etc.) que simplifican la complejidad social y la reducen a debates en los que no hablamos de sujetos sociales actuantes, que son los que encontramos en las prácticas concretas. Este manejo de significantes conlleva implicaciones en la modificación de la esencia de los procesos participativos, ya que el uso de "actores abstractos" ha contribuido a la idealización y simplificación desde las instituciones de las complejas redes locales, mitificando a "la ciudadanía" o "el pueblo".

Cuando intentamos investigar acerca del uso que realizan los jóvenes de los canales de participación social existentes, cómo los valoran, qué dificultades encuentran para participar en ellos, cómo son las relaciones con el resto de actores sociales implicados en los procesos de participación, o qué otras formas alternativas de participación les gustaría desarrollar, también con frecuencia nos adentramos en una 
problemática en la que confluyen factores muy diversos. Por un lado, los procesos de participación forman parte de lo que son las prácticas cotidianas o esporádicas de los jóvenes, lo cual exige adentrarse en el campo de las representaciones simbólicas, los valores y las motivaciones de los sujetos con el fin de comprender cuáles son los distintos sentidos que los jóvenes dan a las prácticas de participación. Por otro lado, los procesos de participación juvenil han de contextualizarse en el marco más amplio de la participación ciudadana adulta, ya que los órganos y canales de participación de la población juvenil (al menos en su dimensión formal) reproducen en gran medida los del mundo adulto, los cuales inducen a unas formas concretas de participación social (básicamente a través de colectivos organizados), quedando un amplio espectro de posibilidades de participación que es necesario explorar para poder comprender muchas de las prácticas de participación juvenil.

Al margen de los distintos enfoques y conceptualizaciones, lo que sí parece cierto en todos los casos es que asistimos a una serie de cambios en las distintas dimensiones de la participación juvenil que entiendo hay que tener muy en cuenta para la comprensión de la realidad existente.

En este sentido quizás lo más llamativo en los resultados de la literatura investigadora de este campo es que la participación juvenil parece ir desplazándose en la actualidad hacia contextos informales, ajenos a espacios diseñados institucionalmente, y donde cada vez más los vínculos vivenciales y existenciales de los sujetos se configuran como el verdadero motor de la acción social. En otras palabras, mientras que en el pasado las identidades colectivas se construían en torno a códigos socioeconómicos e ideológico-políticos, ahora se construyen alrededor de espacios de acción relacionados con la vida cotidiana. La calle y el lenguaje cotidiano, los valores que circulan por la red social, y los símbolos de una comunidad, aparecen como elementos significativos en la articulación de los jóvenes, sus problemas y sus inquietudes. Se desdibujan las grandes metas utópicas a largo plazo, y los escenarios de las prácticas se vinculan primordialmente a la consecución de metas a más inmediatas, realizables y alcanzables. Además, las estructuras de los colectivos juveniles tienden a abandonar los marcos institucionales excesivamente rígidos en favor de redes horizontales que posibilitan la comunicación entre los distintos campos de actuación. Y en estos trazos de diagnóstico, finalmente parece que la necesidad de permanencia de la acción y de las estructuras de participación no supone un rasgo definitorio. Al contrario, se registra un aumento creciente del mecanismo de activaciones y desactivaciones puntuales, en muchas ocasiones con carácter multitemático, en el que los jóvenes entran y salen continuamente de unos procesos de participación caracterizados cada vez más por la flexibilidad y la transitoriedad de la acción.

Estas transformaciones, que tienen un carácter global (niveles de análisis macro y meso) pero se manifiestan y se concretan de múltiples formas en los escenarios cotidianos (nivel micro), poseen sin duda impactos en la forma de ver las relaciones que establecen entre sí los principales actores presentes en el juego participativo: la Administración, las asociaciones y colectivos juveniles, y los que en última instancia deben ser los protagonistas de toda esta historia: la base social, los jóvenes en general.

En la actualidad se cuestionan determinados enfoques, esencialmente vinculados a políticas institucionales, que proyectan en la población juvenil determinadas 
características de las que resulta frecuentemente una visión sesgada de las capacidades participativas de esta población, por las que los jóvenes se encontrarían en una situación de semi-ciudadanía o de ciudadanía incompleta. Así, desde determinadas ópticas del diseño institucional se vincula la imagen de los jóvenes con una idea negativa de la condición juvenil, una condición que atendería a visiones unidimensionales del ciudadano joven, que aparece volcado en el mundo privado, con escasa voluntad de compromiso con los problemas que le rodean, ausente de responsabilidades e inmerso en todas las dificultades que encuentra en el proceso de transición hacia la edad adulta y en su integración dentro de la esfera productiva. Todos estos condicionantes harían perder peso a la importancia que los sujetos jóvenes otorgan a su implicación en la esfera pública. De acuerdo a estas explicaciones a ello respondería el alejamiento de las instituciones y de las prácticas tradicionales de participación social. En los jóvenes españoles parece que asistimos a un aumento de la abstención en el voto, a un descenso en la militancia en partidos políticos y organizaciones ciudadanas tradicionales, a un alejamiento generalizado de las actividades convencionales del espacio participativo, y a una creciente desconfianza en el funcionamiento práctico de las instituciones políticas democráticas.

Para el ámbito estatal español, si seguimos los datos del sondeo de opinión realizado por el Instituto de la Juventud de España sobre participación y cultura política, realizado en 2005 (INJUVE, 2005), se nos muestran resultados que apuntan en el sentido esbozado en el párrafo anterior, aunque ciertamente con contenidos ambivalentes. Los jóvenes españoles muestran un escaso interés por la política ( 3 de cada 4 afirman que le interesa poco o nada), los sentimientos que inspira esta actividad se centran en los calificativos de desconfianza, indiferencia y aburrimiento; pero a la vez afirman estar capacitados en su mayoría para comprender lo que acontece en ese ámbito de la acción pública. Se posicionan en la afirmación mayoritaria de que la democracia es siempre preferible a cualquier otra forma de gobierno $(79.2 \%)$, pero prácticamente la mitad de los encuestados se muestran poco satisfechos con al funcionamiento de la democracia en España. De hecho, la valoración media de ésta en España apenas alcanza el aprobado por parte de los jóvenes en una escala de 0 a 10 (media de valoración de 5.6); un $45 \%$ de los encuestados manifiestan que la sociedad civil en la que vivimos necesita profundas reformas. Dentro de estas calificaciones medias, cuando a los jóvenes se les proponen ciertos aspectos de lo que debe definir la idea de un buen ciudadano, los dos comportamientos propios de la ciudadanía en las democracias representativas tampoco acaban de presentar muy buenas valoraciones: ante la afirmación de que "para ser un buen ciudadano hay que votar en todas las elecciones", apenas se alcanza una valoración media de 5 en la escala (llama la atención que el 67\% de los jóvenes se muestran de acuerdo ante la afirmación de que "no votar es una postura tan legítima como votar"), y si se les pide que se posicionen ante la afirmación de que "para ser un buen ciudadano hay que participar en asociaciones de carácter social o político", la media desciende hasta el 4. En ese sentido, opiniones y prácticas de los sujetos andan bastante alejadas de la idea cristalizada de la excelencia participativa en el ejercicio de la democracia.

Parece por lo tanto que aquellos elementos que definen las prácticas convencionales de participación en el modelo tradicional de democracia representativa no acaban muy bien paradas a ojos de la juventud española. De este tipo de resultados es 
desde donde con cierta asiduidad se articulan los discursos que presentan una condición ciudadana de los jóvenes negativa y alejada de la esfera pública. Este discurso parece consistente, pero no podemos obviar que estamos tomando una parte de la participación ciudadana (las formas y canales tradicionales de participación) por el todo. La idea de participación social desborda en mucho la mera adscripción en los dispositivos diseñados institucionalmente para que los sujetos tomen parte en la esfera pública. Y resulta que cuando amplificamos el contenido y sentido de la acción participativa, hallamos que los resultados en las respuestas de los jóvenes producen una luz distinta sobre la idea estereotipada de implicación cívica o ciudadana de la juventud.

Un primer dato que permite percibir las contradicciones presentes en el análisis de la realidad participativa habitual de la juventud, y que perfila la idea de una reordenación del espacio público, es la coexistencia del bajo interés por los actores y figuras tradicionales con una elevada valoración del sistema democrático. No parece por lo tanto ponerse en duda el marco normativo de la democracia como telón de fondo que otorga legitimidad a las relaciones que acontecen en el espacio público. Además, los jóvenes muestran un acuerdo generalizado en que la política tiene una gran influencia en la vida de cualquier ciudadano, y un interés casi unánime en que se tomen en cuenta sus opiniones a la hora de tomar decisiones que tengan relación con los temas que les afectan.

El resultado, por lo tanto, no parece ser un descontento más o menos crítico u oposición antidemocrática, sino alejamiento y recelo respecto al sistema político, especialmente respecto de aquellos que se ocupan de la toma de decisiones. Más bien, a la luz de los datos, cabe hablar de que los jóvenes manifiestan dificultades para encontrar un soporte adecuado sobre el cual desarrollar su implicación en lo público a través de los canales diseñados institucionalmente, a través de las formas predeterminadas de participación y también, como hemos visto, a través de los actores tradicionales propios de las democracias representativas, inercias todas estas que han generado lógicas en ocasiones muy poco participativas para el mundo participativo juvenil.

Pero encontramos que si se pregunta en torno a otras formas de participación menos convencionales, situadas en el ámbito de la participación no institucionalizada, comienza a esbozarse un nuevo espacio participativo en los jóvenes. Ante esta situación, es posible poner en relevancia el peso cuantitativo que en términos, no ya de opiniones sino de conductas participativas, tienen algunas formas no convencionales de participación. 
Acciones no institucionalizadas de participación social

\begin{tabular}{rr}
\cline { 2 - 2 } "Lo he hecho alguna vez" & "No lo he hecho, pero \\
podría hacerlo"
\end{tabular}

Firmar una petición

$45.2 \%$

$43.3 \%$

Boicotear o comprar ciertos productos por razones políticas o para favorecer el medio ambiente

$21.4 \%$

$54.0 \%$

Fuente: INJUVE (2005)

Como vemos, el arco de conductas participativas no institucionalizadas posee un amplio refuerzo por parte de los jóvenes, tanto en términos de conductas ("lo he hecho alguna vez"), como en términos de predisposición para la conducta ("no lo he hecho pero podría hacerlo"). Se nos muestra así un imaginario participativo que comienza a presentar divergencias respecto a la hipótesis de desafección generalizada de los jóvenes respecto a la esfera pública. Nos hallamos más bien ante un contexto de la participación crítico pero no pasivo, lo que viene a confirmar las ideas ya expresadas por algunos autores como Jorge Benedicto. Coexiste la sensación en los jóvenes de la escasa capacidad de poder incidir de una manera efectiva en la solución de problemas sociales a través del modelo político tradicional, con el desarrollo paralelo de actitudes de implicación cívica. Parece que estamos asistiendo a un desplazamiento de la participación juvenil hacia esferas cívicas y comunitarias, articulándose a través de nuevos marcos organizativos y de significación.

De la lectura de estos datos podemos extraer una primera conclusión: este tipo de acciones que se afrontan desde una perspectiva alejada a los canales institucionales tradicionales de participación, suponen una opción de participación nada desdeñable para la juventud española. Llama por lo tanto la atención especialmente el auge progresivo de la participación no convencional, que cristaliza en un arco de prácticas donde además del componente conductual, se acompaña de una amplia actitud de apoyo por parte de los jóvenes hacia el desarrollo de las formas y los contenidos que estas opciones representan.

La desafección política, como hemos visto, hace referencia a un tipo de participación, aquella fundamentada en las lógicas instituidas, corporativas y codificadas institucionalmente. Pero no podemos vincularla, de acuerdo con los resultados, a otras formas de participación que se muestran ajenas a estos condicionamientos. 
Estas nuevas formas de participación no habría que considerarlas reactivas, al margen o enfrentadas a las prácticas institucionalizadas, sino complementarias a ellas, pero con una naturaleza y una dinámica distinta.

De acuerdo a la información expuesta hasta ahora podemos cuestionar hasta qué punto el discurso afianzado en el mundo adulto que postula el alejamiento y la pasividad de los jóvenes hacia lo público no acaba por abrazar todo el problema (la desafección del joven hacia lo público en general y hacia la política en particular), por lo que quizás sea sólo una parte de la realidad participativa (el cuestionamiento de la lógica de la acción política y de las vías de participación existentes en nuestra democracia representativa). El amplio consenso de los jóvenes en el apoyo hacia nuevos actores y nuevos canales de participación, así como el asentamiento de conductas participativas que se desarrollan al margen del entramado institucional, viene a desvelar una trama más compleja, apoyada en unas características que reconocen la existencia de un sujeto político juvenil no corporativo, atravesado por lógicas no instrumentales y con una percepción implicativa del hecho participativo.

La disfuncionalidad presente por lo tanto habría que buscarla en los mecanismos efectivos de participación (ciudadana en general y juvenil para este caso) propios de las democracias representativas, lo que vendría a sentar las bases de la crisis de un modelo participativo actual que no se circunscribe ni mucho menos al colectivo juvenil.

En este sentido ya hemos comentado que los procesos de participación juvenil han de contextualizarse en el marco más amplio de la participación ciudadana adulta, reproduciendo gran parte de sus inercias y bloqueos. El que el diagnóstico de la realidad existente responda a estos principios se debe en gran medida a la manera en que los diversos actores involucrados en el juego participativo desarrollan su acción. Veamos algunos rasgos.

Del lado de las instituciones, la participación de la juventud en la vida social y política se ha convertido, como hemos visto en la introducción, en un eje discursivo esencial para los gobernantes públicos, pero la existencia de organismos de participación en la práctica limita la intervención de los jóvenes en una canalización a través de las instituciones representativas, bien sean representantes públicos o grupos corporativos ciudadanos (asociaciones). De esta organización de la participación se deriva un modelo participativo altamente reglamentado y con escaso alcance pragmático en la intervención de los jóvenes en la esfera pública. La participación suele estar regulada casi exclusivamente a través del derecho administrativo, y por lo tanto comporta una marcada vocación de reglamentación formal, que incorpora habitualmente elementos informativos y consultivos, pero no suele prever canales y formas que posibiliten procesos a través de los cuales los jóvenes puedan incidir realmente en cuestiones públicas que consideran de interés. Se percibe además, desde análisis relacionales, una verticalidad de relaciones que mantienen las instituciones con el resto de actores (asociaciones juveniles y jóvenes en general), lo que provoca con frecuencia conflictividad e inercias clientelares como elemento adicional vinculado a la dificultad de transformación del espacio participativo, impidiendo un desarrollo armónico de éste y generando bloqueos de muy diversa índole. El resultado en muchas ocasiones deriva en una desafección mutua entre instituciones y ciudadanos que alimenta una falla participativa crecientemente pronunciada. En realidad, la práctica habitual del quehacer 
institucional en materia de juventud cristaliza en una financiación de la oferta, diseñada esencialmente desde dentro de la propia Administración, pero hallamos escasos referentes de financiación de la demanda que parte de los propios jóvenes. Visto así, el éxito o fracaso de las políticas depende esencialmente de la experiencia, la habilidad o la intuición de los cuadros técnicos y políticos responsables de las áreas de juventud, para incluir en las programaciones contenidos que sean aceptados por los diferentes segmentos de población juvenil.

El formalismo, la excesiva reglamentación de los procesos participativos, la necesidad de acreditación como condición para la participación presente en muchas figuras de participación juvenil impulsadas desde las instituciones, incorporan obstáculos a menudo insalvables para formas emergentes de participación no formal, que en muchas ocasiones poseen una enorme potencialidad como activadores de la participación juvenil de grupos de la base social. Grupos que normalmente no pretenden tener vínculos con el nivel institucional pero que se acercan a él con el fin de solicitar apoyo para el desarrollo de actividades concretas que muchas veces involucran a un gran número de jóvenes. La reglamentación y la acreditación en los procesos de participación exigen normalmente de los actores cierta experiencia y un conocimiento de los códigos de relación con la Administración, aportar garantías existencia -que no actividad- estable en el tiempo (estatutos, memorias, formularios para subvenciones, etc.). El resultado en muchos casos es el control de los órganos clásicos de participación por parte de grandes organizaciones o colectivos con suficiente experiencia para poder cumplir con todos los requisitos necesarios para la Administración, limitando la capacidad de actuación de otros grupos que, ante las dificultades que supone lograr la colaboración institucional, optan por desarrollar su actividad al margen de los espacios de participación formal.

Del lado del sector asociativo, que supone el elemento articulador de referencia en el modelo de participación juvenil actual, es posible establecer diferentes problemas relacionados con el papel que desempeñan las asociaciones en los procesos participativos. Cabe hablar, de acuerdo a diversas investigaciones realizadas de la existencia de una crisis de convocatoria en las asociaciones juveniles, tanto interna (la implicación de los propios socios) como externa (la participación de otros jóvenes en las actividades que plantea el proyecto asociativo). También es posible determinar la presencia de una concepción endogámica del juego participativo, en la que prima el proyecto individual de la propia asociación frente a los nexos relacionales con otros colectivos. E incluso es posible hablar en términos de competitividad entre colectivos en el planteamiento de los procesos de participación y asignación de recursos. Vinculado al problema que este texto aborda, dentro y fuera del sector asociativo se plantea actualmente con intensidad el debate en torno a una crisis de representación de las asociaciones dentro del espacio participativo, representación que constituye la base legitimadora de su presencia en los órganos de participación propios del modelo de participación predominante. Esta presencia de las asociaciones está fundada de acuerdo a su papel de interlocución como entes representativos de las diferentes orientaciones y segmentos juveniles sobre los que desarrollan su actividad. Si los jóvenes cuestionan la lógica de la representación, estamos en realidad disparando hacia la línea de flotación de un modelo de participación basado en el asociacionismo. Al eliminar de la ecuación participativa la legitimidad que otorga el sistema representativo a la figura de las asociaciones, y sumarle la escasa valoración que atribuyen los jóvenes a los agentes 
políticos en lo referente a la representación de los intereses y preferencias de la juventud, ciertamente tenemos que hablar de un modelo participativo en crisis.

La vinculación simbólica del eje participación-asociacionismo supone una de las vías fundamentales para el fomento de la participación, pero no la única; por consiguiente limitarse a la explotación de ese camino implica con frecuencia renunciar a la potencialidad que generan los focos de participación no formal. La idea de nuevas figuras de participación abiertas como son los Foros Jóvenes o las Asambleas y Encuentros participativos no se oponen a los órganos tradicionales de participación (consejos de la juventud, comisiones, plataformas, etc.) sino que más bien los complementan y refuerzan.

Bien es cierto que el esbozo de la situación no es aplicable a todo contexto y lugar, pero allá donde se han puesto en marcha experiencias innovadoras de participación juvenil la descripción realizada ha constituido en la mayoría de los casos el escenario de partida.

\section{Elementos propositivos y estrategias implicativas.}

De acuerdo a la situación descrita parece conveniente y necesario, si asumimos una óptica de profundización en los contenidos de la participación juvenil, desarrollar un replanteamiento en el espacio participativo que proponga una nueva articulación de relaciones entre los actores presentes (instituciones, asociaciones y jóvenes), que sustituya la lógica de la re-presentación por otra de presentación, capaz de registrar mejor la implicación de los sujetos en el planteamiento y resolución de problemas e intereses, y que establezca nuevos soportes para la información y la comunicación. Distintas formas de participar construyen distintas realidades, y el que la escena participativa se oriente en el refuerzo de las lógicas presentes en la actualidad o desarrolle acciones estratégicas hacia modelos instituyentes de participación, abre la puerta a distintos futuros. Los modelos instituyentes constituyen en muchos casos el espejo, el negativo (o quizás sea mejor llamarlo el positivo) de la definición que de la situación de la participación juvenil realizan la mayoría de los actores implicados en el ámbito participativo.

Y en ese sentido a lo largo de Europa comienzan a emerger en muchos lugares (algunos de ellos estratégicos) modelos concretos de participación instituyente de la juventud que van introduciendo nuevos cauces de relación entre los distintos actores que entran en escena en el juego de la participación. El común denominador de este tipo de experiencias participativas innovadoras radica en que el eje orientador de los procesos se ancla en torno al objetivo de dar respuesta a las preferencias que los jóvenes plantean, primando las programaciones basadas en la demanda presente en las redes sociales, frente a las tradicionales que se fundaban en la oferta institucional.

Para alcanzar este horizonte, la mayoría de nuevas estrategias y procesos aparecen ligados a las etiquetas de "gestión participativa" o "democracia participativa", que comportan un diseño del espacio de participación muy similar. Se trata de experiencias que se constituyen como herramientas de participación multisectorial, abiertas a una multiplicidad de áreas de diseño-acción-reflexión. El diseño participativo de programaciones plantea así una llamada a la posibilidad de emprender proyectos 
institucionales encabalgados en la acción concreta, pragmática y operativa, y en la praxis que deviene de la reflexión colectiva para poder volver a actuar sobre la realidad de partida, alejándose así de planteamientos tecnocráticos y aprovechando la seducción simbólica que debería posibilitar la construcción de espacios de participación horizontal abiertos y no corporativos. La lógica práxica aborda este dilema desde la idea de que la acción contribuye o alimenta la necesaria reflexión y, paralelamente, nutre además otro proceso todavía más importante, la implicación. Los jóvenes, si son protagonistas de las acciones, si poseen capacidad real y efectiva para decidir, desarrollarán con mucha más facilidad un sentimiento de apropiación o de implicación que ayuda a dar sentido a lo que se hace.

Son experiencias por lo tanto que persiguen altos niveles de implicación de los jóvenes dentro de la escala participativa, que abren el marco normativo de la participación a jóvenes no organizados, siguiendo una perspectiva inclusiva de la participación, y constituyen además procesos que intentan integrar de manera efectiva a los jóvenes en la acción pública. Se trata por lo tanto de procesos que comprenden altos grados en tres dimensiones claves que son susceptibles de ser valoradas en cualquier figura participativa: influencia, intensidad e inclusividad. Dichas dimensiones además definen en gran medida su naturaleza innovadora respecto a las formas tradicionales de participación, que es lo que las hace relevantes en este texto. Aclarémoslas:

- Inclusividad: grado de apertura a la participación de los jóvenes no organizados formalmente.

- Intensidad: capacidad pedagógica en la que las acciones comunicativas favorecen la apropiación de la información a través de la deliberación por parte de los participantes.

- Influencia: orientación de los procesos de participación en relación a la acción del gobierno o las instituciones.

Precisamente las limitaciones presentadas en la descripción de la situación actual de la participación juvenil son las que justifican la necesidad de diseñar mecanismos participativos que sean capaces de avanzar lo más lejos posible en las tres dimensiones expresadas. Esto es, procesos lo más inclusivos posibles (permitiendo la participación de cualquier joven que así lo decida), que desarrollen la mayor intensidad posible (facilitando que los participantes desarrollen todas las acciones que comprende el proceso), y capaces de influir en las políticas públicas (reconociendo la vinculación de las decisiones alcanzadas con la acción institucional).

La dimensión de inclusividad es la que hace referencia, como ya hemos comentado, a qué jóvenes se convierten en elegibles para el proceso participativo y cómo se convierten en participantes. Respondería a la pregunta de quiénes participan. En ese sentido un proceso participativo podría tener una configuración normativa restrictiva en la selección de participantes a partir de la cual, por ejemplo, solo estén llamados a participar los representantes electos de la ciudadanía, esto es, los políticos. Dentro de esta concepción restringida, todavía podríamos distinguir entre los procesos en los que solamente están habilitados para participar aquellos representantes electos que ejercen 
funciones de gobierno, y aquellos en los que pueden participar el conjunto de representantes, formen o no parte del gobierno municipal.

Un segundo grado de apertura, todavía circunscrito al ámbito institucional, estaría protagonizado por procesos en los que toman parte tanto los políticos como personal experto de la Administración, que bien podrían ser técnicos de la Administración local en sus diferentes escalas, bien podrían ser también investigadores o analistas contratados por su conocimiento de la temática a tratar dentro de la programación de juventud, o bien de forma extensiva podría ser cualquier tipo de agente vinculado a la Administración.

Un tercer grado de apertura vendría dado por la incorporación al proceso participativo del mundo asociativo juvenil o de las organizaciones y colectivos formales con presencia y capacidad legal de actuación dentro del ámbito de juventud. El proceso ya estaría circunscrito sólo al ámbito de la Administración sino que se abriría a la población a través de la lógica representativa de las asociaciones juveniles sobre los diferentes segmentos de jóvenes del municipio. Estas asociaciones, que conformarían un espacio selectivo de participación, representarían los intereses de los jóvenes y actuarían como interlocutor de éstos con las instituciones en el desarrollo de demandas e intereses.

Un cuarto grado de inclusividad lo ofrece la llamada a la participación de la esfera pública, pero una llamada en la que los jóvenes, aunque participen individualmente, no asumen un papel activo, sino que generalmente son objeto de consulta o información sin que necesariamente deban adoptar un papel de implicación activa en el proceso. A pesar de ello podemos presuponer que la puesta en marcha del proceso participativo proporciona incentivos estructurales que hacen el hecho participativo más atractivo a jóvenes que de otra forma no suelen participar.

El grado más ambicioso de inclusividad en las figuras participativas juveniles vendría dado por la apertura a los jóvenes en general, ya con un papel más o menos activo si se incorporan al desarrollo de los procesos. En este caso podemos hablar de dos posibilidades o estrategias distintas. Una sería la selección aleatoria de jóvenes para su colaboración y participación individual, y la otra la constituye la generación de la posibilidad de que los jóvenes de forma autónoma se "auto-seleccionen" para participar, posibilidad que refleja el mayor alcance de inclusividad por cuanto cualquier joven tiene capacidad y legitimidad reconocida institucionalmente para tomar parte en las diferentes acciones del proceso participativo. Bajo esta última opción, no se perseguiría tanto alcanzar una capacidad representativa de los participantes respecto al conjunto de la población (lógica a la que obedece en muchas ocasiones la selección aleatoria), sino más bien alcanzar un subconjunto de la población juvenil implicado en la resolución de problemas y cuestiones que afectan a la juventud. 
La escala que define los grados de inclusividad quedaría dispuesta de la siguiente manera:

\begin{tabular}{|c|c|c|c|c|c|c|}
\hline INCLUSIVIDAD & $\begin{array}{l}\text { Representantes } \\
\text { electos }\end{array}$ & $\begin{array}{l}\text { Expertos de la } \\
\text { Administración }\end{array}$ & $\begin{array}{l}\text { Asociaciones } \\
\text { ycolectivos } \\
\text { formales }\end{array}$ & $\begin{array}{l}\text { Esfera } \\
\text { pública } \\
\text { difusa }\end{array}$ & $\begin{array}{l}\text { Jóvenes } \\
\text { Seleccionados } \\
\text { al azar }\end{array}$ & $\begin{array}{l}\text { Jóvenes } \\
\text { auto- } \\
\text { seleccionados }\end{array}$ \\
\hline Menor in & lusividad & & & & \multicolumn{2}{|c|}{ Mayor inclusividad } \\
\hline
\end{tabular}

Una segunda dimensión a partir de la cual podemos ubicar las diferentes experiencias participativas juveniles es la intensidad, que describiría cómo interactúan, intercambian información y toman decisiones los participantes, lo que trae a la escena la función y la capacidad pedagógica que tienen estos procesos en la apropiación de la información por parte de los sujetos que desarrollan las acciones participativas. Esta dimensión respondería a la pregunta básica de cómo participan.

Así, el nivel menos ambicioso de interacción hallaríamos procesos en los que los jóvenes participantes concurren habilitados solamente para escuchar lo que acontece. Corresponde a este nivel una concepción pasiva de la participación, en la que los sujetos participan como espectadores, generalmente con el fin de recibir información acerca de proyectos o políticas concretas que son implementadas por otros actores.

Un nivel mayor de intensidad lo encontraríamos en aquellas experiencias que posibilitan que los jóvenes puedan expresar opiniones y preferencias. Los sujetos participantes ya no solo escuchan lo que otros dicen sino que están habilitados para establecer una comunicación bidireccional, expresando sus opiniones o intereses en relación a las temáticas propuestas para debate, aunque sin capacidad efectiva de articularlos dentro de la lógica que propone el espacio participativo.

Esto sí sería posible en el siguiente grado de intensidad, en el que a los jóvenes se les reconoce la capacidad para desarrollar preferencias e intereses, abriendo de esta manera un flujo de comunicación que ya adquiere un carácter deliberativo, por cuanto permite un proceso interactivo con ciertas dosis de horizontalidad que facilita la exploración mutua de intereses y la transformación de las preferencias a través del debate común.

Pero sería posible ir más allá en la acción deliberativa y dotarla de una capacidad ejecutiva que permita sancionar los acuerdos adoptados, habilitando a los jóvenes participantes a votar y tomar decisiones. Cabe señalar que en ocasiones la negociación y la votación no tiene porqué ir ligada necesariamente a un proceso previo de deliberación común, sino que puede resultar un simple mecanismo de acuerdos de mayorías sobre el planteamiento de intereses no sometidos a la acción comunicativa. De ahí que esta escala no posea un carácter estrictamente lineal.

Quedaría un grado más en esta escala que tampoco posee estrictamente carácter lineal, por cuanto es transversal a todos los grados anteriores, y es la adquisición de conocimientos técnicos. Conforme aumenta la intensidad de la participación de los sujetos juveniles también crece paralelamente los problemas y los condicionantes de 
naturaleza técnica a la que se deben enfrentar, puesto que se adentran en cuestiones tecnoadministrativas que en los niveles menos ambiciosos quedan reservados para su resolución en el ámbito institucional. Pero es precisamente la comprensión de este tipo de determinantes que condicionan en muchas ocasiones la factibilidad técnica, legal o competencial de las iniciativas juveniles la que aporta un mayor grado pedagógico a este tipo de procesos, la que conduce a una mayor apropiación de la información ya que permite contemplar las posibilidades en su conjunto, y de ahí el situarlo al final de la escala propuesta. La escala relativa a la intensidad quedaría formulada del siguiente modo:

\begin{tabular}{|c|c|c|c|c|c|c|}
\hline INTENSIDAD & $\begin{array}{l}\text { Escuchar } \\
\text { como espectador }\end{array}$ & $\begin{array}{l}\text { Expresar } \\
\text { preferencias }\end{array}$ & $\begin{array}{l}\text { Desarrollar } \\
\text { preferencias }\end{array}$ & Deliberar & $\begin{array}{l}\text { Negociar } \\
\text { y votar }\end{array}$ & $\begin{array}{l}\text { Adquirir } \\
\text { conocimientos técnicos }\end{array}$ \\
\hline \multicolumn{3}{|c|}{ Menor intensidad } & & & \multicolumn{2}{|c|}{ Mayor intensidad } \\
\hline
\end{tabular}

Finalmente, la última dimensión que nos permite distribuir los distintos procesos de participación juvenil es la referente al concepto de influencia, y se centra en la orientación de los procesos de participación en relación a la acción de gobierno. O dicho en otras palabras, mide la capacidad de impacto efectivo y real del proceso participativo, la autoridad en definitiva, sobre la información que de él se genera. Esta dimensión respondería a la pregunta de para qué se participa y dentro de ella nos encontramos, al igual que en las dimensiones anteriores, con un arco gradual de posibilidades.

De acuerdo con una lógica de aumento gradual de influencia de los procesos, los mecanismos menos ambiciosos son aquellos en los cuales los participantes no poseen ninguna expectativa de influir en la política institucional relacionada con el proceso participativo al cual se incorpora. La influencia del joven en este nivel es mínima, y solamente existe el recurso de la persuasión, la argumentación o la seducción como únicas posibilidades de influir en las decisiones que otros adoptarán.

El siguiente grado lo constituiría la capacidad de los participantes y los propios procesos para, cuando menos, generar información a la población juvenil, con lo cual la influencia ya no queda circunscrita al ámbito interno de los procesos sino que trasciende al exterior y se intenta socializar la información a través de estrategias de difusión (campañas, informes, medios de comunicación, etc.), estrategias a través de las cuales se influye también en la política pública de juventud.

Un mayor grado de influencia sería el que aportan los procesos que reconocen en su esencia una lógica consultiva. En estos mecanismos se habilita ya un canal en el que, aunque los responsables de las políticas de juventud siguen manteniendo intacta su autoridad, reconocen la utilidad de la recepción de opiniones o consejos por parte de los participantes y jóvenes en general.

Más allá, y coincidiendo con las escalas clásicas de participación encontramos aquellos mecanismos participativos en los cuales los jóvenes disponen de la influencia 
suficiente como para tomar decisiones vinculantes para la puesta en marcha o la concreción de políticas o programaciones de juventud. En este nivel podríamos hablar ya en términos de empoderamiento de los participantes, por cuanto el proceso deliberativo conduce no solo a consensos o acuerdos respecto al bien común, sino que además estos consensos se plasman en decisiones ejecutivas a partir de la existencia de un compromiso institucional de llevarlas a cabo.

El siguiente grado de influencia residiría ya más allá del mero hecho de disponer de capacidad de decisión, y se traduce en la creación de mecanismos que permitan conjuntamente a jóvenes participantes e instituciones gestionar la forma en que se desarrollan las políticas públicas fruto del proceso de participación juvenil, así como establecer una vigilancia del cumplimiento de estos acuerdos.

Finalmente, el nivel más ambicioso de influencia se situaría en la conformación de procesos participativos que sentaran una relación horizontal y simétrica entre jóvenes participantes y gobierno, plasmado en fórmulas de co-gobierno de la acción pública. La escala referente a la dimensión de influencia quedaría plasmada de la siguiente forma:

\begin{tabular}{|c|c|c|c|c|c|c|}
\hline INFLUENCIA & Persuasión & Información pública & Consulta & Decisión & Co-gestión & Co-gobierno \\
\hline \multicolumn{2}{|c|}{ Menor influencia } & & & \multicolumn{3}{|c|}{ Mayor influencia } \\
\hline
\end{tabular}

De acuerdo a toda esta información, podemos intentar sintetizar los contenidos de las páginas anteriores estableciendo una serie de criterios de participación que permitan valorar a la vez que imaginar nuevas figuras participativas en el ámbito juvenil.

Qué etiqueta adopte la figura o el proceso participativo concreto es cuestión de poca importancia. Lo verdaderamente relevante es cómo incorpora este conjunto de criterios con el fin de generar un espacio participativo abierto a las nuevas lógicas de participación demandadas por los jóvenes, lo que sin duda incide directamente sobre los futuros del laberinto de la participación juvenil. 


\section{Criterios de participación en los procesos participativos juveniles}

\begin{tabular}{|c|c|c|c|}
\hline $\begin{array}{l}\text { Ámbito del } \\
\text { espacio } \\
\text { participativo } \\
\text { en el que se } \\
\text { sitúa }\end{array}$ & $\begin{array}{l}\text { Criterio de } \\
\text { participación }\end{array}$ & Descripción & $\begin{array}{c}\text { Dimensión } \\
\text { de } \\
\text { participación } \\
\text { sobre la que } \\
\text { incide }\end{array}$ \\
\hline \multirow{2}{*}{$\begin{array}{l}\text { Interacción } \\
\text { comunicativa }\end{array}$} & $\begin{array}{ll}\text { Capacidad } & \text { pedagógica } \\
\text { del proceso } & \end{array}$ & $\begin{array}{l}\text { Grado de aprendizaje de los jóvenes } \\
\text { participantes: adquisición de nuevas } \\
\text { habilidades cognitivas y organizacionales }\end{array}$ & Intensidad \\
\hline & $\begin{array}{ll}\text { Comprensión } & \text { del } \\
\text { proceso por parte de los } \\
\text { participantes }\end{array}$ & $\begin{array}{l}\text { Comprensión de los objetivos, acciones, } \\
\text { límites y alcances del proceso participativo }\end{array}$ & Intensidad \\
\hline \multirow{2}{*}{ Información } & $\begin{array}{l}\text { Forma en la que se } \\
\text { gestiona la información }\end{array}$ & $\begin{array}{l}\text { Cómo y cuando circula la información dentro } \\
\text { del proceso, tanto en sentido vertical (entre } \\
\text { niveles) como horizontal }\end{array}$ & $\begin{array}{l}\text { Inclusividad } \\
\text { Intensidad }\end{array}$ \\
\hline & $\begin{array}{lrr}\text { Espacios } & \text { para } & \text { la } \\
\text { devolución } & \text { de } & \text { la } \\
\text { información } & & \\
\end{array}$ & $\begin{array}{l}\text { Modos y espacios a través de los cuales se } \\
\text { rinde cuentas del proceso y los resultados }\end{array}$ & $\begin{array}{l}\text { Inclusividad } \\
\text { Intensidad } \\
\text { Influencia }\end{array}$ \\
\hline \multirow[b]{2}{*}{$\begin{array}{l}\text { Apertura } \\
\text { participativa }\end{array}$} & $\begin{array}{l}\text { Jóvenes habilitados para } \\
\text { participar }\end{array}$ & $\begin{array}{l}\text { Determinación de la "unidad participativa": } \\
\text { participación de base asociativa, mixta, o } \\
\text { individual. }\end{array}$ & Inclusividad \\
\hline & $\begin{array}{l}\text { Incorporación efectiva } \\
\text { de segmentos de jóvenes } \\
\text { ausentes }\end{array}$ & $\begin{array}{l}\text { Incorporación de segmentos de jóvenes } \\
\text { tradicionalmente ausentes del juego } \\
\text { participativo, tanto en términos de categorías } \\
\text { sociales (franjas de edad, lugar de residencia) } \\
\text { como de grupos específicos (inmigrantes, } \\
\text { rentas bajas, etc.) }\end{array}$ & Inclusividad \\
\hline \multirow{3}{*}{ Deliberación } & $\begin{array}{l}\text { Tiempos establecidos } \\
\text { para la deliberación }\end{array}$ & $\begin{array}{l}\text { Espacios y tiempos destinados al debate en } \\
\text { torno al propio proceso y tomar decisiones }\end{array}$ & Intensidad \\
\hline & $\begin{array}{l}\text { Forma en que se } \\
\text { alcanzan acuerdos }\end{array}$ & Por consensos, por mayorías, por criterios. & $\begin{array}{l}\text { Intensidad } \\
\text { Influencia }\end{array}$ \\
\hline & $\begin{array}{l}\text { Modo de resolución de } \\
\text { conflictos }\end{array}$ & $\begin{array}{l}\text { Se resuelven dentro del propio proceso o se } \\
\text { resuelven desde una instancia externa }\end{array}$ & Intensidad \\
\hline \multirow[t]{2}{*}{ Decisión } & $\begin{array}{l}\text { Existencia de criterios } \\
\text { para la priorización de } \\
\text { necesidades y demandas }\end{array}$ & $\begin{array}{l}\text { Establecimiento de criterios de redistribución } \\
\text { social para primar la satisfacción de } \\
\text { necesidades o la reducción de desigualdad } \\
\text { social }\end{array}$ & Intensidad \\
\hline & $\begin{array}{l}\text { Grado de transparencia } \\
\text { en la toma de decisiones }\end{array}$ & $\begin{array}{l}\text { Claridad y comprensión de las formas en que } \\
\text { se toman las decisiones en los distintos } \\
\text { momentos del proceso }\end{array}$ & $\begin{array}{l}\text { Inclusividad } \\
\text { Intensidad }\end{array}$ \\
\hline \multirow{3}{*}{ Apropiación } & Tutela del proceso & Nivel que tutela la marcha del proceso & $\begin{array}{l}\text { Intensidad } \\
\text { Influencia }\end{array}$ \\
\hline & Sostenibilidad & $\begin{array}{l}\text { Capacidad de pervivencia del proceso al } \\
\text { margen de la acción institucional }\end{array}$ & $\begin{array}{l}\text { Intensidad } \\
\text { Influencia }\end{array}$ \\
\hline & $\begin{array}{l}\text { Seguimiento/ control de } \\
\text { los acuerdos }\end{array}$ & $\begin{array}{l}\text { Espacios u órganos que se establecen para la } \\
\text { fiscalización y el control sobre los acuerdos }\end{array}$ & $\begin{array}{l}\text { Intensidad } \\
\text { Influencia }\end{array}$ \\
\hline \multirow{4}{*}{$\begin{array}{l}\text { Compromiso } \\
\text { institucional }\end{array}$} & Voluntad política & $\begin{array}{l}\text { Existencia de voluntad política real para } \\
\text { impulsar el proceso y garantizar acuerdo }\end{array}$ & Influencia \\
\hline & $\begin{array}{l}\text { Transversalidad } \\
\text { interdepartamental }\end{array}$ & $\begin{array}{l}\text { Grado de corresponsabilidad de las áreas } \\
\text { institucionales en el proceso }\end{array}$ & Influencia \\
\hline & $\begin{array}{l}\text { Recursos públicos que se } \\
\text { someten a debate }\end{array}$ & $\begin{array}{l}\text { Naturaleza de los recursos públicos } \\
\text { sometidos a debate o deliberación, y } \\
\text { proporción en relación a los recursos totales }\end{array}$ & Influencia \\
\hline & $\begin{array}{lll}\text { Soporte legal } & \text { del } \\
\text { proceso }\end{array}$ & $\begin{array}{l}\text { Traducción normativa y legal del marco } \\
\text { regulador del proceso }\end{array}$ & $\begin{array}{l}\text { Intensidad } \\
\text { Influencia }\end{array}$ \\
\hline
\end{tabular}

